\title{
REPAYMENT INCENTIVES AND THE DISTRIBUTION OF GAINS FROM GROUP LENDING
}

\author{
Jean-Marie Baland \\ Email: jean-marie.baland@fundp.ac.be \\ University of Namur
}

Rohini Somanathan

Email: rohini@ias.edu

Delhi School of Economics

University of Delhi

\&

Institute for Advanced Study, Princeton

Zaki Wahhaj

Email: zaki.wahhaj@qeh.ox.ac.uk

University of Oxford

Working Paper No. 192 


\title{
Repayment incentives and the distribution of gains from group lending*
}

\author{
Jean-Marie Baland $^{\dagger} \quad$ Rohini Somanathan ${ }^{\ddagger}$ Zaki Wahhaj $\S$
}

November 12, 2010

\begin{abstract}
Group loans with joint liability have been a distinguishing feature of many microfinance programs. While such lending has benefitted millions of borrowers, major lending institutions have acknowledged their limited impact among the very poor and have recently favored individual contracts. This paper attempts to understand these empirical patterns using a model in which there is a single investment project and access to credit is limited by weak repayment incentives. We show that in the absence of large social sanctions, the poorest borrowers are offered individual and not group contracts. When both types of contracts are feasible, the relative gains from group loans are shown to be decreasing in loan size. We compare the role of bank enforcement with social sanctions and find that bank enforcement is more effective in increasing outreach while social sanctions raise the welfare of infra-marginal borrowers. Finally, we explore the welfare effects of group size and find that those requiring small loans are better served by larger groups but group size effects are, in general, ambiguous.
\end{abstract}

Keywords: microcredit, joint-liability, group lending, repayment incentives, social sanctions. JEL codes: I38, G21, O12, O16

${ }^{*}$ We are thankful to Greg Fisher, Eliana la Ferrara, Maitreesh Ghatak, Parikhit Gosh, Andrew Newman, E. Somanathan and many seminar participants for useful comments. Jean-Marie Baland is grateful for the financial support provided by the Belgian Program on Inter-University Poles of Attraction, the Actions de Recherches Concertees program and a grant from the European Research Council (AdG-230290-SSD). Rohini Somanathan would like to thank the Leon Levy Foundation for support of her membership at the Institute for Advanced Study.

${ }^{\dagger}$ University of Namur (jean-marie.baland@fundp.ac.be).

${ }_{\ddagger}^{\ddagger}$ Delhi School of Economics, Delhi University and Institute for Advanced Study, Princeton (rohini@ias.edu).

§University of Oxford (zaki.wahhaj@qeh.ox.ac.uk) 


\section{Introduction}

The ideology and practice of poverty alleviation has been deeply influenced by the idea that access to credit can empower the poor. Microfinance programs around the world cover millions of borrowers and are provided under a variety of different institutional arrangements. Although overall gains from such lending are widely acknowledged, there is concern about their failure to reach those at the bottom of the income distribution. There is a lively debate, but little consensus, on how these institutions can be better designed to serve poor families. An important question within this debate is whether group loans with joint liability provide marginal borrowers with adequate repayment incentives.

The Grameen Bank of Bangladesh first popularized group loans in the 1970s and similar approaches were subsequently adopted by hundreds of organizations across the world. It was believed that joint liability would generate social pressure on borrowers to repay loans and help create a financially sustainable model of lending. In recent years, this strategy has been questioned and individual loan contracts have become an integral part of microfinance. In 2002, the Grameen Bank replaced their hallmark model of group lending with Grameen II, under which all members were individually liable for their loans and the group structure was maintained mainly to foster solidarity within villages. Following the introduction of the new system, the total number of borrowers increased from 3 to 8 million. ${ }^{1}$ This trend is by no means universal. An interesting contrast is provided by the microfinance sector in India which adheres fairly strictly to joint liability contracts. ${ }^{2}$

\footnotetext{
${ }^{1}$ Wright et al. (2006) examine membership trends until 2005 and report that "Grameen took 27 years to reach 2.5 million members- and then doubled that in the full establishment of Grameen II". The Grameen Bank's own website currently reports membership of about 8 million. Particularly interesting is the admission by the bank that very poor individuals are often best served outside groups (Grameen Bank, 2009):

A destitute person does not have to belong to a group...Bringing a destitute woman to a level where she can become a regular member of a group will be considered as a great achievement of a group.

${ }^{2}$ The Indian microfinance sector is defined to include members of Self Help Groups (SHGs) and clients of microfinance institutions (MFIs). On March 31, 2007, there were an estimated 39.9 million SHG members and 14.1 million MFI clients (Srinivasan (2009), p 5, Table 1.2). Examples of large microfinance institutions that use group loans with joint liability can be found in Field and Pande (2008) and Banerjee et al. (2009). Ghate (2008) contains a classification of 129 recognized microfinance institutions in India according to the type of lending contracts offered (Table A.2).
} 
The empirical literature on the selection and performance of borrowers in the microfinance sector suggests that the poorest families are under-represented in credit groups both through biases in branch location and the selection of clients and members within villages (Morduch, 1988). Once groups are created, attrition rates appear to be higher for the socially disadvantaged, perhaps because they have less to gain from group membership and because of exclusionary practices within groups (Baland et al., 2008). Giné and Karlan (2009) examine the role of contractual structure on repayment rates through the randomized assignment of individual and joint liability across similar borrowers in the Philippines. They find that, on average, there is no significant difference in these rates across the two regimes.

This paper is motivated by the correlations observed between poverty and the benefits from group lending. We would like to explain why group lending is viable and valuable in providing credit for moderately poor households but not for the very poor. There are many plausible reasons for this which are not directly related to the incentive structure of credit contracts. Poor families may not have the characteristics or networks required for entrepreneurial success or transactions costs of lending to them may be high. We abstract from these differences and focus on the relative gains from group and individual lending for a population of borrowers with identical investment opportunities but heterogeneous initial wealth. We show that borrowers requiring the smallest loans face the most favorable interest rates under joint liability and, for high enough loans sizes, borrowers may be strictly better off with individual liability than with group loans.

Our work is most closely related to a well-established theoretical literature that relates joint liability to borrower incentives and illustrates multiple mechanisms through which group loans can affect investment decisions and repayment rates. ${ }^{3}$ Groups may keep out risky borrowers (Ghatak, 1999) and monitor their effort and choice of projects (Stiglitz, 1990; Banerjee et al., 1994) To understand the distributional effects of group lending, we ignore questions of borrower and project selection and focus on the incentives for loan repayment under alternative liability regimes. This was first studied by Besley and Coate (1995) in the context of two-person groups with identical loan requirements. In their model, joint liability has ambiguous effects on repayment rates. While it allows for the pooling of risks within a group, it also increases the total repayment burden for successful borrowers. This may lead to group default in cases where one of the borrowers would have repaid the bank under an individual contract.

\footnotetext{
${ }^{3}$ Comprehensive surveys of this literature can be found in Ghatak and Guinnane (1999) and Armendariz de Aghion and Morduch (2005).
} 
We build on this basic idea using a more general framework which allows us to explore the differential benefits of group lending to borrowers with varying initial levels of wealth. We use $n$-person groups and show how interest rates under group lending are determined endogenously by expected repayment rates. Larger per member loans limit risk-pooling possibilities and are associated with lower repayment rates. As a result, equilibrium interest rates and expected bank sanctions are increasing in loan size under joint liability contracts while they do not vary for individual loans. It is this difference that generates many of our results. Given project characteristics, poorer borrowers are more likely to be sanctioned not only because their loans are bigger but also because interest rates on these loans are higher. This higher cost of borrowing for the poor has not appeared in the two-person, partial equilibrium framework used in the joint liability literature but has been central to the study of income dynamics and the efficiency of investment decisions in the presence of credit constraints (Galor and Zeira, 1993; Banerjee and Newman, 1993).

Our model can also be used to assess the relative importance of formal and informal mechanisms for enforcing credit contracts and inofrm the design of policies for greater credit outreach among the poor. Discussions of informal networks for contract enforcement often imply that social sanctions are near-perfect substitutes for the punishment practices of the formal banking system. We illustrate a more nuanced interaction of these two enforcement mechanisms. We show that stronger bank sanctions always extend credit market access among the poor while social sanctions do so only under certain conditions. Social sanctions on the other hand are more effective in raising the welfare of inframarginal borrowers because these sanctions are never implemented in equilibrium.

We also explore the effects of group size since organizations vary quite widely in the sizes of groups that they allow. We show that for groups with small enough loans, two member groups are never optimal. For larger loan sizes, the effects of group size on borrower welfare can go either way and we provide some examples that illustrate this non-monotonicity.

Taken together, these results suggest that joint liability can increase borrower welfare but gains from such lending depend on loan sizes and therefore on the initial distribution of wealth. Its ability to provide the poor access to credit depends both on the strength of social networks within a group and on the characteristics of the projects undertaken. In many cases, the poorest households may be best served by providing them individual loans on more favorable terms and promoting alternative programs of poverty alleviation. Strategies to expand rural credit probably require a mix of contractual arrangements and the excessive focus on group lending that we have seen in recent years may be misplaced. 


\section{The model}

Our principal unit of analysis is a set of risk neutral households each of whom can choose to invest in a project. The project requires one unit of capital and no other inputs. ${ }^{4}$ It yields a return $\rho$ with probability $\pi$ and zero otherwise. Households with inadequate capital can borrow from a competitive banking system either as individuals or as members of groups of size $n$ with joint liability. Project returns are observed within the group but are unobservable to the bank.

Banks offer depositors a gross return of $r$ which is the opportunity cost of bank funds. The interest rates charged to lenders vary with repayment rates in a manner that equates the expected return from all contracts to $r$. Banks have available a non-pecuniary sanction $K$ which can be imposed on defaulting borrowers. In the case of non-repayment of group loans, all group members are sanctioned $K$. In addition to bank sanctions, groups may impose social sanctions which inflict a utility cost $\gamma$ on sanctioned members and are costless to others in the group. We follow the existing literature on group lending by assuming these sanctions are exogenously given. ${ }^{5}$

We begin by characterizing individual contracts. Unsuccessful borrowers must default on their loans because their projects have zero returns. Banks limit loan sizes to ensure all successful borrowers prefer repayment to sanctions and break even when charging a gross interest rate $\frac{r}{\pi}$. Total payments for a household borrowing $L$ are then given by $\frac{L r}{\pi}$ and the largest incentive compatible loan is

$$
L_{i}=\frac{\pi K}{r} .
$$

If $K<\frac{r}{\pi}$, the largest available loan is less than one and households with initial wealth less than $\left(1-L_{i}\right)$ cannot invest in the project. We assume that this is indeed the case because we are interested in whether joint liability can extend credit access to households who are not eligible for individual contracts.

For households borrowing an amount $L$, the expected net gain from investment is $\pi\left(\rho-\frac{r}{\pi} L\right)-$

\footnotetext{
${ }^{4}$ Costs of effort are easily incorporated. In our model the project returns can be interpreted as being net of these costs. While we have in mind the self-employment projects financed by many microfinance organizations, we do not introduce this term because no effort decision is modeled.

${ }^{5}$ In practice the nature of bank and social sanctions is complex and might vary with borrower characteristics. By abstracting from these complexities, we are better able to compare the effects of joint and individual liability within a given enforcement structure.
} 
$(1-\pi) K-r w$, which simplifies to

$$
U_{i}=\pi \rho-r-(1-\pi) K
$$

As long as $U_{i}$ is positive, individuals strictly prefer investing in the project. This requires the return $\rho$ to be greater than

$$
\bar{\rho}=\frac{1-\pi}{\pi} K+\frac{r}{\pi}
$$

Group contracts are complicated by the fact that interest rates depend on loan size and the repayment strategies of members. As in most such coordination games, there are many equilibria. We restrict our attention to the symmetric repayment equilibrium with the smallest positive contributions by each member. This assumes away coordination problems within the group and allows us to better focus on the relationship between loan sizes and interest rates.

To see how interest rates vary by loan size, consider a group with $n$ members with the same initial wealth $w \cdot{ }^{6}$ Each member requires a loan of $L=(1-w)$ to invest in the project and the group borrows $n L$. The interest rate charged on this amount depends on the bank's assessment of the probability of repayment, or equivalently, the fraction of such groups that will repay the loan. Denote by $B(j)$, the binomial probability of $j$ or more successes within the group ${ }^{7}$ and let $\tilde{j} \leq n$ be the smallest integer for which

$$
\frac{n}{\tilde{j}} \frac{r}{B(\tilde{j})} L \leq \min (\rho, K+\gamma)
$$

If groups repay whenever they have at least $\tilde{j}$ successful projects, banks break even by charging an interest rate $\frac{r}{B(\tilde{j})}$. The contribution of each successful member is $\frac{n}{j} \frac{r}{B(j)} L$ where $j \geq \tilde{j}$. We require this amount to be lower than project returns $\rho$ and the sum of bank and social sanctions $K+\gamma$. The definition of $\tilde{j}$ in (4) ensures that this is the case. The group lending contract is

\footnotetext{
${ }^{6}$ The assumption of uniform wealth within groups allows us to abstract from questions of within group redistribution to better focus on the risk pooling function of joint liability which is our main interest. In practice, most group lending programs have tried to ensure that members within groups are similar in terms of their initial endowments. At the start of the Indian microcredit program for example, non-government organizations were issued guidelines by the central banking authorities that explicitly directed them to foster savings and credit groups among households of "homogeneous background and interest" (National Bank for Agriculture and Rural Development, 1992).

${ }^{7}$ To be more precise, this is the probability of at least $j$ successes in $n$ trials when the probability of success on each trial equal to $\pi$. We refer to this by $B(n, j, \pi)$ whenever there is ambiguity about the $n$ and $\pi$ in question.
} 
given by $\left(L, \frac{r}{B(\mathfrak{j})}, K\right)$. Whenever the number of successes in a group happens to be greater than $\tilde{j}$, actual contributions are lower than the maximum contributions that members are willing to make. $^{8}$

It is worth specifying how social sanctions are used by the group to enforce repayment. The interest rate on a group loan is based on the probability of $\tilde{j}$ successes. If fewer successes are realized in the group, the group defaults, the bank sanctions all members and no social sanctions are used. If, on the other hand, more than $\tilde{j}$ successes are realized, each successful member contributing less than their equal share $\frac{n}{j} \frac{r}{B(j)} L$ towards repayment faces social sanctions. ${ }^{9}$

We summarize the above discussion before proceeding to our results. For each household, initial wealth defines the loan required to undertake the project. Depending on the size of this loan, it may be available under an individual contract or a joint liability loan within an $n$ member group or both, or neither. If the loan is available, it is taken under the contractual arrangment that best suits the borrower, investments are made and returns are realized. These returns are observed by members within groups but not by the bank. In the case of individual contracts, each household with a successful project chooses between reimbursing the bank and being sanctioned $K$. Unsuccessful households are always sanctioned. In the case of group loans, successful members simultaneously decide on contributions towards bank repayment after project returns are realized. If available contributions are high enough, repayment is made. If not, the bank sanctions each member $K$ and successful members who do not contribute their share may be subject to social sanctions $\gamma$.

\section{Credit outreach under joint liability}

We are now in a position to examine the conditions under which joint liability extends credit to those who have no access to individual loan contracts. Denote by $L_{g}$ the largest loan that is offered under joint liability. This is the value of $L$ at which the function $j B(j)$ takes its maximum value and (4) holds with equality. The following lemma establishes the shape of this

\footnotetext{
${ }^{8}$ There may be other integers for which (4) holds. We are interested in the smallest of these because it corresponds to the lowest interest rate and therefore the most favorable group contract.

${ }^{9}$ Notice that the size of these sanctions does not depend on the number of successful projects or the fraction of members who contribute. One can think of them as simply arising from a group rule that stipulates social penalties on members that do not contribute enough.
} 


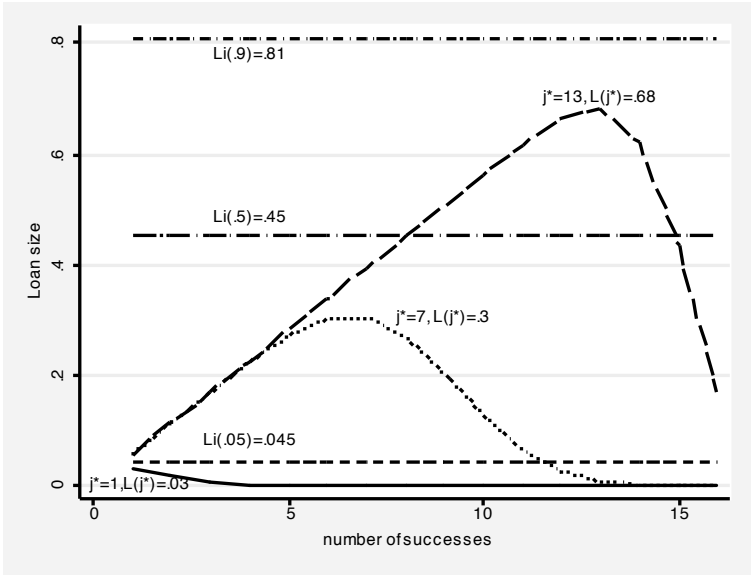

Figure 1: Maximum Group Loans

function and will be useful in establishing many of our results. All proofs are in the appendix.

Lemma 1. The function $j B(j)$ is single-peaked. It starts at zero, takes the value $n \pi^{n}$ at $j=n$ and attains a maximum at $j^{*} \leq\lceil n \pi\rceil$. If $\pi<\frac{1}{n}$, it is decreasing for $j \geq 1$ and, if $\pi>\frac{n(n-1)}{1+n(n-1)}$, it is increasing throughout. ${ }^{10}$

Figure 1 illustrates the maximum loan size available under individual and group contracts for three different levels of project uncertainty, namely $\pi=\{.05, .5, .9\}$. In each case, the group size $n=16, \frac{K}{r}=.9$ and social sanctions $\gamma=0$. The largest individual loans available are represented by the three horizontal lines. Using Equation (4), the maximum group loans are given by $L_{g}=\frac{K}{r} \frac{j^{*} B\left(j^{*}\right)}{n}$. When $\pi=.05$, the function $j B(j)$ is maximized at $j=1$ and this is therefore the value of $j$ corresponding to the largest group loan. In this case the largest group loan is 0.03 while the largest individual loan is .045 . In the other two cases, the function is hump shaped. When $\pi=.5$, the largest group loan corresponds to $j^{*}=7$ which is below the mean $n \pi=8$ and in each case $j^{*}$ is below $n \pi$. The maximum group loans are always below the largest individual loans. The following proposition establishes that this is generally true when groups do not have access to social sanctions.

Proposition 1. In the absence of social sanctions the largest loan available in a group lending contract is strictly smaller than in an individual contract.

Proposition 1 implies that, absent social sanctions, group lending does not reach those who

${ }^{10}\lceil x\rceil$ denotes the smallest integer greater than or equal to $x$. 
are denied individual loans. This result is driven by the fact that banks extract less from projects financed by group loans. With no social sanctions, individuals, whether or not they are in groups, can be induced to pay the bank at most $K$. Under an individual contract, all successful projects repay the bank and therefore a fraction $\pi$ of all loans are repaid. Under group lending, groups with too few successes default and pay nothing, while in groups where more than a fraction $\pi$ of their members succeed, each of them pays less than they would have under an individual loan. These leakages cause interest rates on group loans to rise above those on individual loans and (4) cannot therefore hold for loans of size $L_{i}$.

The ambiguous effects of joint liability in the absence of social sanctions have been recognized in earlier work. Besley and Coate (1995) show that joint liability can increase the burden of debt on those with successful projects and thereby lower repayment rates. Our contribution here is to link repayment rates to required loan sizes and to the interest rates charged by banks. At $L_{i}$, we show that repayment rates are always lower under group liability and interest rates are higher. As a result, the incentive compatibility condition in (4) fails and group loans of this size are not feasible.

A natural next question is the degree to which social sanctions can extend outreach. Such sanctions relax the incentive compatibility constraint and allow a larger share of project returns to be extracted from each successful member. This increases possibilities for risk pooling and allows groups to repay the bank loan in states with fewer successful projects. Notice however from (4) that higher sanctions can only improve repayment incentives as long as the total value of bank and social sanctions are below the project return $\rho$. Beyond this point group members have nothing left to contribute and it is not repayment incentives but project returns that restrict the size of group loans. The following proposition outlines the conditions under which social sanctions allow households requiring more than $L_{i}$ to obtain credit through group loans.

Proposition 2. Let social sanctions $\gamma \geq \bar{\rho}-K$. Then $L_{i}$ is a feasible group loan if either of the following conditions hold:

1. $n=2$

2. $\pi \leq \frac{1}{2}$ and $n \pi$ is an integer

3. $\pi \leq \frac{1}{4}$

In contrast, for large $\pi, \rho=\bar{\rho}$ and $n>2$, there always exist loan sizes which will be offered as individual loans but not as group loans even if social sanctions are arbitrarily large. 
The above result highlights the risk-pooling aspect of group lending. When project uncertainty or risk is high, returns in the good state must be correspondingly high and social sanctions allow these to be extracted. Note also that the two-member groups that have been exclusive focus of much of the existing literature on group lending are a particular case whose properties do not generalize to larger groups.

\section{Contractual choice and welfare}

We have so far discussed the maximum size of group and individual loans that banks are willing to offer. For those eligible for both types of loans, contractual choice will depend on their relative welfare gains under the two regimes. The net gain from investing in the project under individual liability has already been derived in Equation (2) and shown to be independent of the amount borrowed. For group loans, recall that $\tilde{j}$ is the minimum number of successes required for repayment. Denote by $\pi_{j}$ the binomial probability of exactly $j$ successes in $n$ trails with a probability of success $\pi$ in each trial.

The expected utility gain for each member can be derived as the sum of two terms, one for states in which the group defaults and the other for which repayment occurs:

$$
U_{g}=\sum_{j=0}^{\tilde{j}-1} \pi_{j}\left(\frac{j}{n} \rho-K-r w\right)+\sum_{j=\tilde{j}}^{n} \pi_{j}\left(\frac{j}{n}\left(\rho-\frac{n}{j} \frac{r}{B(\tilde{j})} L\right)-r w\right) .
$$

The first sum on the RHS is the expected gain for all states in which the group defaults because $j<\tilde{j}$ and the bank sanctions all members. In such cases, the member keeps the return $\rho$ if his project is successful, which happens with probability $\frac{j}{n}$. The second sum is for all states with bank repayment and all successful members contributing their share. We simplify the above expression to obtain

$$
U_{g}(\tilde{j})=\pi \rho-r-K \sum_{j=0}^{\tilde{j}-1} \pi_{j}=\pi \rho-r-(1-B(\tilde{j})) K
$$

using $B(\tilde{j})=\sum_{j=\tilde{j}}^{n} \pi_{j}, L=(1-w)$ and the expectation of a binomial distribution $\sum_{j=0}^{n} j \pi_{j}=n \pi$. Since $\tilde{j}$ is increasing in loan-size and $U_{g}(\tilde{j})$ is decreasing in $\tilde{j}$, groups with larger loans derive lower benefits from group loans. 
We can now use (2) and (5) to express the difference in utility between a group loan and an individual loan of the same size as

$$
U_{g}-U_{i}=[B(\tilde{j})-\pi] K
$$

The gain from group relative to individual contracts is simply equal to the difference in the probability of being sanctioned by the bank. This is because banks interest rates are set to extract the same amount in expected terms from each contract and no social sanctions are applied in equilibrium. Payments in each state by groups and households differ, but these differences are offset by the probability with which those states occur. We therefore have the following result:

Proposition 3. The benefits from group contracts are decreasing in loan size. Group loans are preferred to individual loans if the probability of group repayment is greater than $\pi$.

For small enough loans, group contracts are always strictly preferred. To see this, consider a loan that can be repaid with only one success in the group. Since $B(1)=1-(1-\pi)^{n}$, Equation (6) can be written as

$$
U_{g}-U_{i}=\left[1-(1-\pi)^{n}-\pi\right] K=\left[(1-\pi)-(1-\pi)^{n}\right] K>0
$$

In general, the gain from group loans need not be positive. It may well be that a group loan is feasible, in that groups have the correct incentives to repay, yet the expected utility of each their members is higher under an individual contract. Since the minimum number of successes required for repaying a loan $\tilde{j}(L)$ is increasing in loan size and the probability of obtaining these, $B(\tilde{j})$ is decreasing in $\tilde{j}$, we may have $B(\tilde{j})<\pi$. As an example, note that when $\pi$ approaches 1 , the largest group loans are those require all $n$ members to have successful projects. In this case $B(n)=\pi^{n}$. Since this is less than $\pi$, individual loans, if available, are strictly preferred.

We are now in a position to describe the equilibrium distribution of group and individual contracts for different levels of wealth and with and without social sanctions. For a given investment project, those with high enough initial wealth always select group contracts. In the absence of social sanctions, the largest group loan is smaller than the largest individual loan and marginal investors always take individual loans. Those with wealth below $\left(1-L_{i}\right)$ cannot invest. Social sanctions raise both the maximum size of group loans and the benefits from group lending. When project uncertainty and social sanctions are both high, individual loans are not chosen in equilibrium. This is illustrated in Figure 2. 


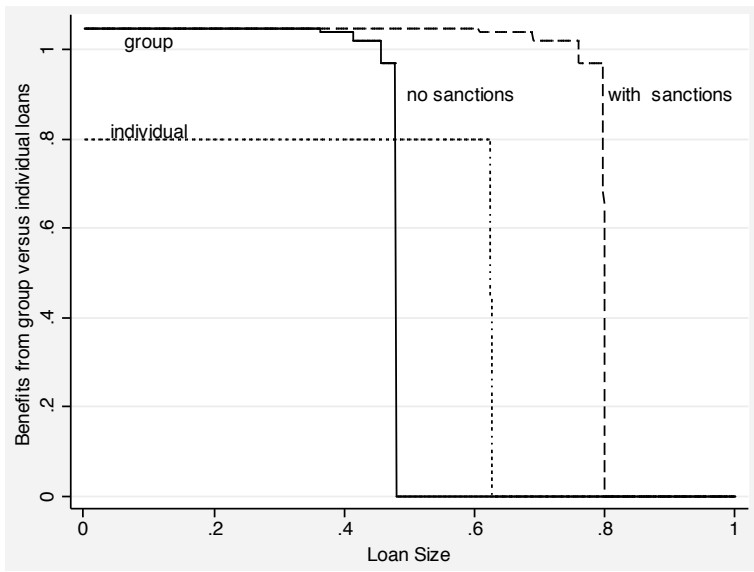

Figure 2: Loan size and contractual choice

\section{Formal and informal enforcement}

Informal networks have been recognized as playing an important role in facilitating exchange when formal institutions for contract enforcement are weak. The sanctions imposed within these networks have often been perceived as a near substitute for legal enforcement. In this section, we revisit this question in the context of microfinance by comparing the effects of bank and social sanctions on credit outreach and borrower welfare.

We have already shown that in the absence of social sanctions, the largest group loans $L_{g}$ are smaller than corresponding individual loans, $L_{i}$. We now examine how each of these change with a marginal increase in bank and social sanctions respectively. Recall that $L_{i}=\frac{\pi K}{r}$ and assuming $\rho \geq K+\gamma, L_{g}=\frac{j^{*} B\left(j^{*}\right)}{n r}(K+\gamma)$. We see from these expressions that changes in bank and social sanctions have identical marginal effects on group loans and that the effect of bank sanctions, $K$, on individual loans is bigger than on group loans because $n \pi>j^{*} B\left(j^{*}\right)$ (Proposition 1). This leads us to the following result:

Proposition 4. Social sanctions are never more effective than bank sanctions in increasing credit outreach. If $L_{g}>L_{i}$ social sanctions and bank sanctions have identical effects on the maximum size of group loans. If $L_{i} \geq L_{g}$, maximal outreach is achieved through bank sanctions on individual loans.

We see from the above discussion that enforcement through the banking system always does 
better in increasing access to credit. In contrast, we now show that social sanctions are much more effective than bank sanctions is raising the utility of those already using group loans.

Proposition 5. For borrowers choosing group loans, higher social sanctions always raise welfare. Bank sanctions can sometimes raise welfare but to a lesser extent. For individual loans, higher bank sanctions always lower welfare.

Since social sanctions are never used in equilibrium, they always raise the benefits from group lending because they result in a more favorable group contract. The threat of being sanctioned allows groups to extract more from successful projects and the value of $\tilde{j}$ in their group contract is therefore lower. Bank sanctions on the other hand, are used in equilibrium and may either increase or decrease borrower utility depending on whether the gains from a lower probability of being sanctioned by the bank are offset by the higher level of the sanction when it is imposed. For individual loans, higher bank sanctions always lower utility because their frequency is insensitive to the level of the sanction and stays unchanged at $(1-\pi)$. We see therefore that both types of sanctions increase the relative gain from group loans.

\section{The effects of group size}

We do not have a complete characterization of the relationship between group size and welfare. Since the probability of repayment for an $n$ person group is based on the number of successes as defined by a binomial distribution, small changes in loan size can lead to jumps in repayment probabilities and rule out a smooth relationship between the sizes of loans and groups. When required loan sizes are sufficiently small, we are able to show that large groups pool risk more effectively and two member groups are never optimal. At the other extreme, when the group loan is at its maximum level, we are able to put a lower bound on the project success probability $\pi$ under which larger groups always result in lower borrower welfare. For arbitrary loan amounts and project characteristics, increases in group size can either raise or lower welfare. We have the following result:

Proposition 6. For sufficiently small loans, a fall in group size lowers welfare and two member groups are never optimal. For the largest available group loans, borrower welfare is always

decreasing in group size if the probability of project sucess $\pi \geq \frac{n(n-1)}{1+n(n-1)}$. For intermediate loan sizes, borrower welfare can either increase or decrease in group size. 
To see why small loan amounts favor large groups, consider a group of three that can repay the group loan as long as one members succeeds. This implies that at the required loan size, $\hat{L}$, the following version of the incentive compatibility condition in Equation (4) holds:

$$
3 \cdot \frac{r}{B(3,1, \pi)} \hat{L} \leq \min (\rho, K+\gamma)
$$

For a loan of the same size taken by a two-member group, the corresponding incentive compatibility constraint would continue to hold because the LHS would now be smaller at $2 \cdot \frac{r}{B(2,1, \pi)} \hat{L}$ and the RHS of both constraints would be identical. But since $B(n, 1, \pi)$ is strictly increasing in $n$, welfare would be lower for a group of 2 which requires the same per member loan, $\hat{L}$. The same argument would hold for other values of group size $n$; if the required group loan can be repaid with only one success, a fall in group size always lowers borrower welfare.

Now consider the largest possible loan for a group of $n$ members and a project success probability, $\pi \geq \frac{n(n-1)}{1+n(n-1)}$. We know from Lemma 1 that repayment of such a loan requires all $n$ members to succeed. For group of size $(n-1)$ a loan of this size is shown to be feasible and it is welfare improving because the probability of all group projects being successful is decreasing in $n$.

Moving away from these limit cases we find non-monotonic effects of group size. Figure 3 illustrates how the optimal group contract and the per member gains from group over individual loans changes as a function of group size. We consider all even-sized groups of between 2 and 40 members, each member requires $L=.25$ and the project success probability is $\pi=.5$. Bank and social sanctions are .6 and .4 respectively and the risk free interest rate is 25 per cent. Starting with a group of size 2 , an increase in size initially lowers welfare because the optimal contract for sizes of 4 and 6 requires at least half of the members to succeed, and the probability of this event is decreasing in size. For a group of size 8, an additional and opposing effect comes into play as the fraction of successes $\tilde{j}$ in the group lending contract falls below one-half. The scissor pattern seen in the gains from group lending mirrors a similar pattern in the fraction of successes $\frac{\tilde{j}}{n}$ implied by the group contract.

The details of how group size influences borrower welfare outside the limit cases outlined in Proposition 6 will vary with the size of the loan and project characterisitcs. The above example is only to illustrate that general results on size effects are elusive. 


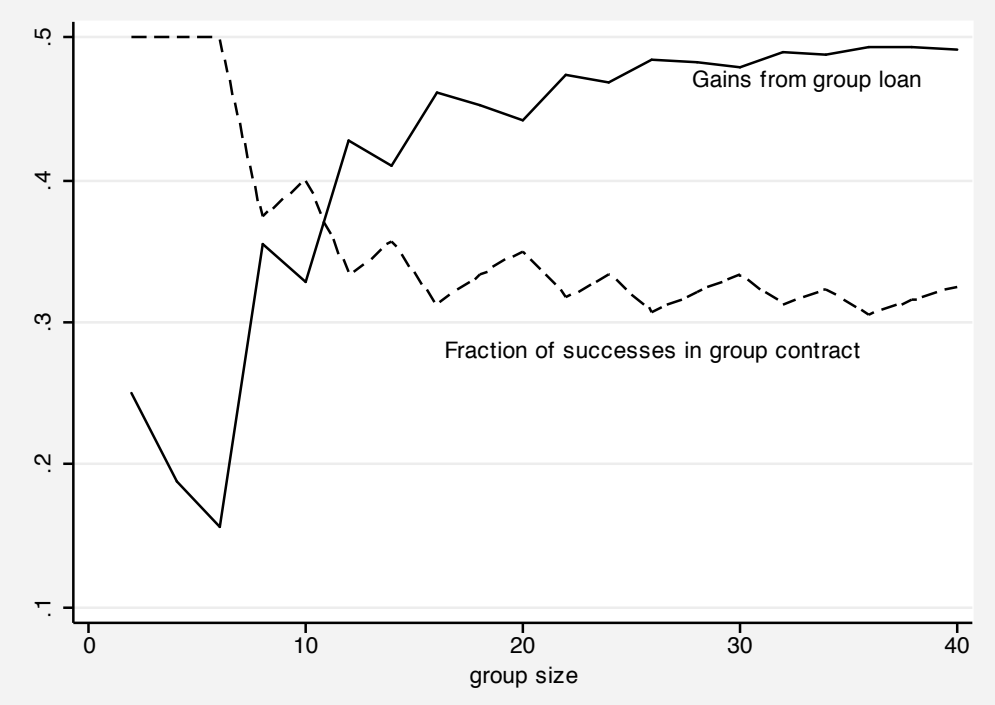

Figure 3: Group size effects $(\pi=.5, L=.25, K+\gamma=1, r=1.2)$

\section{Conclusion}

This paper is motivated by the now common observation that group loans with joint liability appear better suited for the moderately poor than the very poor. We show why this might be true by examining how repayment rates and credit contracts vary by loan size. Our paper builds on the standard approach in the group lending literature in two important respects. First, we move away from two person groups to arbitrary group sizes. Second, we allow interest rates for each type of contract to vary by repayment rates. Using this framework we find that for a given investment project, poorer borrowers face a higher cost of capital under joint liability and the gains from group lending are therefore increasing in initial borrower wealth.

Our model isolates only one mechansim, namely repayment incentives, that can help explain the relationship between borrower wealth and the prevalence of group lending contracts. We have abstracted from questions of project choice and group selection that have been important in the literature on joint liability. These are questions that are worth exploring further. Our results in this paper suggest that the use of a more general framework than has been used so far to examine these issues can help us better understand the distribution of gains from group lending. 


\section{Appendix}

\section{Proof of Lemma 1}

The function $j B(j)$ takes the value zero at $j=0$ and is positive for all $j>0$. We begin by showing that it is decreasing to the right of $\lceil n \pi\rceil$. We then establish that it is single-peaked by showing that, if for some $j^{*}<\lceil n \pi\rceil, j B(j)>(j+1) B(j+1)$, then this relationship holds for all $j$ in the range $j^{*} \leq j \leq\lfloor n \pi\rfloor$. Finally, for the case where $\lceil n \pi\rceil=n$, we derive the lower bound on $\pi$ given in the lemma for which $j B(j)$ is increasing throughout.

1. $j B(j)$ is decreasing to the right of $j=\lceil n \pi\rceil$ :

Consider $n>j \geq\lceil n \pi\rceil$. The function $j B(j)$ is strictly decreasing at $j$ if $j B(j)>$ $(j+1) B(j+1)$. The LHS can be written as $j B(j+1)+j \pi_{j}$ and rearranging terms gives us the condition:

$$
j \pi_{j}>B(j+1)
$$

The binomial probabilities, $\pi_{j}$ and $\pi_{j+1}$ are respectively

$$
\pi_{j}=\pi^{j}(1-\pi)^{n-j} \frac{n !}{j !(n-j) !}
$$

and

$$
\pi_{j+1}=\pi^{j+1}(1-\pi)^{n-j-1} \frac{n !}{(j+1) !(n-j-1) !} .
$$

Writing $\pi_{j}$ in terms of $\pi_{j+1}$ and multiplying by $j$, we get

$$
j \pi_{j}=\left(\frac{j}{n-j} \frac{1-\pi}{\pi}\right)(j+1) \pi_{j+1}
$$

But $\frac{j}{n-j} \frac{1-\pi}{\pi} \geq 1$ if $j \geq n \pi$, which implies

$$
j \pi_{j} \geq \pi_{j+1}+j \pi_{j+1}
$$

In the same way, we can express $j \pi_{j+1}$ as a function of $\pi_{j+2}$ :

$$
j \pi_{j+1}=\left(\frac{j}{n-j-1} \frac{1-\pi}{\pi}\right)(j+2) \pi_{j+2} .
$$

Since $\frac{j}{n-j-1} \frac{1-\pi}{\pi}>1$ for $j \geq n \pi$,

$$
j \pi_{j+1}>\pi_{j+2}+j \pi_{j+2}
$$


Combining the expressions for $j \pi_{j}$ and $j \pi_{j+1}$ we get

$$
j \pi_{j}>\pi_{j+1}+\pi_{j+2}+j \pi_{j+2}
$$

For all $k \leq n-1$, we can continue expressing $j \pi_{k}$ as a function of $\pi_{k+1}$, and we obtain:

$$
j \pi_{j}>\sum_{k=j+1}^{n} \pi_{k}=B(j+1) .
$$

As a result, $j B(j)$ is strictly decreasing to the right of $\lceil n \pi\rceil$.

2. $j B(j)$ is single-peaked to the left of $\lceil n \pi\rceil$ :

We use the property of a Binomial distribution that the mode $M$ of the distribution is either $\lfloor n \pi\rfloor$ or $\lceil n \pi\rceil$ (Kaas and Buhrman, 1980).

Let us first consider any value $j^{\prime}, 1 \leq j^{\prime} \leq\lfloor n \pi\rfloor$ for which $j B(j)$ is increasing at $j^{\prime}$. From (8), this implies that $j^{\prime} \pi_{j^{\prime}} \leq B\left(j^{\prime}+1\right)$. But since $\pi_{j}$ is maximized at the mode, which at least as large as $j^{\prime}$, the LHS $j \pi_{j}$ is increasing for all $j<j^{\prime}$. The upper tail probability, $B(j+1)$ is strictly decreasing in $j$ throughout. It follows that $\forall j<j^{\prime}, j B(j)$ must be increasing at $j$.

Now suppose that $j^{\prime \prime} \leq\lfloor n \pi\rfloor$ is the smallest value of $j$ at which $j B(j)$ is decreasing, or equivalently, $j \pi_{j} \geq B(j+1)$. Since $j^{\prime \prime}$ is less than the mode, this inequality must hold for all $j$ between $j^{\prime \prime}$ and the mode by the same reasoning given above, i.e. $j \pi_{j}$ is increasing in $j$ until the mode and $B(j+1)$ is strictly decreasing in $j$. If no such value exists, $j B(j)$ is increasing throughout.

3. For $j B(j)$ to be increasing throughout, we require the mode to be greater than $(n-1)$ and in addition, using $(8),(n-1) \pi_{n-1}<\pi_{n}$. We can rewrite this inequality as

$$
n(n-1) \pi^{n-1}(1-\pi)<\pi^{n}
$$

or

$$
\pi>\frac{n(n-1)}{1+n(n-1)}
$$

However, at the values of $\pi$ satisfying the above condition, $n \pi>n-1$ so that $M \geq n-1$.

\section{Proof of Proposition 1}


The largest loan available under an individual contract is given by $L_{i}=\frac{K \pi}{r}$ as seen in equation (1). This is not feasible as a group loan if, for all $0<j \leq n$,

$$
\frac{n}{j} L_{i} \frac{r}{B(j)}>K
$$

Using (1), $K$ can be expressed in terms of $L_{i}$ and we can rewrite the above condition as

$$
n \pi>j B(j)
$$

We show that this is always true. The LHS is the expectation of a Binomial distribution with parameters $n$ and $\pi$ and can be expressed as:

$$
n \pi=\sum_{k=0}^{n} k \pi_{k}>\sum_{k=j}^{n} k \pi_{k} \geq j \sum_{k=j}^{n} \pi_{k}=j B(j) .
$$

\section{Proof of Proposition 2}

We start with the first part of the proposition and show that individual contracts can be implemented as group loans under the stated conditions on $n$ and $\pi$. When social sanctions are higher than $\bar{\rho}-K$, we show that even if returns take their minimum value of $\bar{\rho}$, repayment is feasible for low values of $\pi$.

A group of loan of size $L_{i}$ can be repaid if there exists a value of $j^{\prime}$ such that

$$
\frac{n}{j^{\prime}} \frac{r}{B\left(j^{\prime}\right)} L_{i} \leq \bar{\rho}
$$

Substituting for $L_{i}$ from Equation (1) and for $\bar{\rho}$ from Equation (3), this condition can be rewritten as

$$
\frac{n}{j^{\prime}} \frac{\pi}{B\left(j^{\prime}\right)} K \leq \frac{1-\pi}{\pi} K+\frac{r}{\pi}
$$

Now, since $L_{i}=\frac{\pi K}{r}<1, \frac{r}{\pi}>K$. It is therefore enough to show that

$$
\frac{n}{j^{\prime}} \frac{\pi}{B\left(j^{\prime}\right)} K \leq \frac{1-\pi}{\pi} K+K
$$

or equivalently

$$
\frac{n}{j^{\prime}} \frac{\pi}{B\left(j^{\prime}\right)} \leq \frac{1}{\pi} .
$$


The rest of the proof uses two well-known results on the binomial distribution from Kaas and Buhrman (1980). The first is that for integer values of the mean $n \pi$, the median, $m$, is equal to the mean. The second is that for non-integer values of the mean, the median is either $\lceil n \pi\rceil$, the smallest integer above the mean or $\lfloor n \pi\rfloor$, the largest integer below the mean.

We will first prove the result for integer values of $n \pi$, with $\pi \leq \frac{1}{2}$. We will then consider non-integer values of $n \pi$ and finally show that $L_{i}$ is always a feasible group loan when $n=2$.

If $n \pi$ is an integer, set $j^{\prime}=n \pi=m$. The inequality in (10) is now

$$
\pi \leq B(m)
$$

But since $m$ is the median, $B(m) \geq \frac{1}{2}$ so with $\pi \leq \frac{1}{2}$ this is always true.

Now consider non-integer values of the mean. The median in this case must either be $\lceil n \pi\rceil$ or $\lfloor n \pi\rfloor$. If the median $m=\lceil n \pi\rceil$ then set $j^{\prime}=\lceil n \pi\rceil$ in (10). Since $n \pi<\lceil n \pi\rceil$, the LHS is of (10) is smaller than when $n \pi$ is an integer and the result goes through a fortiori.

If instead $m=\lfloor n \pi\rfloor$, consider first $j^{\prime}=\lceil n \pi\rceil=1$. In this case $n \pi$ is strictly less than 1 and (10) holds if $B(1)>\pi$. But $B(1)=1-(1-\pi)^{n}$ so this is always true. If $\lceil n \pi\rceil>1$, set $j^{\prime}=\lfloor n \pi\rfloor=m$. We can now rewrite (10) as

$$
\frac{n}{m} \frac{\pi}{B(m)} \leq \frac{1}{\pi}
$$

But since $n \pi<\lceil n \pi\rceil$, it is enough to show that

$$
\pi \leq \frac{m}{m+1} B(m)
$$

The ratio $\frac{m}{m+1}$ is increasing in $m$ and takes its minimum value of $\frac{1}{2}$ when $j=2$. The minimum value taken by $B(m)$ is also $\frac{1}{2}$, so the above inequality holds whenever $\pi \leq \frac{1}{4}$.

For the case where $n=2$, set $j^{\prime}=2$ and (10) can now be expressed as $\frac{2}{2} \frac{\pi^{2}}{B(2)} \leq 1$. But $B(2)=\pi^{2}$, so this holds with equality.

We finally show that for large $\pi$ and $n>2$, there always exist loan sizes that will be implemented as individual but not group contracts.

By Lemma 1, the function $j B(j)$ is maximized at $j^{*}=n$ when $\pi>\frac{n(n-1)}{1+n(n-1)}$ and we know that $B(n)=\pi^{n}$. If the group loan is equal to $L_{i}$, each successful member in the group is required to 
contribute $\frac{r}{\pi^{n}} L_{i}$. while the minimal return to the project $\bar{\rho}$ is

$$
\bar{\rho}=\frac{(1-\pi)}{\pi} K+\frac{r}{\pi}=\frac{(1-\pi)}{\pi} \frac{r L_{i}}{\pi}+\frac{r}{\pi}
$$

Required payments are therefore higher than $\bar{\rho}$ whenever

$$
L_{i}>\frac{\pi^{n}}{\pi-\pi^{n-1}+\pi^{n}} .
$$

If $n>2$, the RHS of the above expression is smaller than one and there exist loan sizes $L_{i}$ that are not feasible group loans even for arbitrarily high social sanctions.

\section{Proof of Proposition 4}

Since we are considering the case where sanctions limit the size of group loans $(\rho>K+\gamma)$, the largest individual and group loans are given respectively by

$$
L_{i}=\frac{\pi K}{r} \quad \text { and } \quad L_{g}=\frac{j^{*} B\left(j^{*}\right)}{n r}(K+\gamma)
$$

The effect of bank sanctions on the maximum value of the two types of loans is given by

$$
\frac{\partial L_{i}}{\partial K}=\frac{\pi}{r} \quad \text { and } \quad \frac{\partial L_{g}}{\partial K}=\frac{j^{*} B\left(j^{*}\right)}{n r}
$$

Note that since $j^{*} B\left(j^{*}\right)$ depends only on group size $n$ and the probability of project success, $\pi$, it is unaffected by changes in $K$. Furthermore, Proposition 1 shows that $j^{*} B\left(j^{*}\right)<n \pi$ which implies that $\frac{\partial L_{g}}{\partial K}=<\frac{\partial L_{i}}{\partial K}$.

We have therefore shown that the marginal effect of sanctions is positive for both types of loans and larger for individual loans. If the initial level of $L_{i}$ is at least equal to $L_{g}$, then the largest individual loan after the increase in sanctions must also be greater than the largest group loan.

\section{Proof of Proposition 5}

The utility from individual and group loans is given by Equations (2) and (5) respectively. The marginal effect of a rise in social sanctions for group loans is given by $\left[B\left(j^{\prime}\right)-B(j)\right] * K$, where $j^{\prime}$ is the number of successes required in the most favorable group contract for a particular loan size after the change in social sanctions and $j$ is the corresponding number before the change. Since $j^{\prime} \leq j$, the second term is non-negative and the relative gain from group lending goes up. 
In a similar fashion, we can derive the change in welfare from an increase in bank sanctions. The marginal effect of higher sanctions, $K$, on individual loans is given by

$$
\frac{\partial U_{i}}{\partial K}=-(1-\pi)
$$

This reflects the higher expected cost of the sanction. For group loans, we once again need to account of the change in the most favorable contract offered for each loan size. The change in utility from group loans is now given by

$$
\frac{\partial U_{g}}{\partial K}=-\left[1-B\left(j^{\prime}\right)\right]+\left[B\left(j^{\prime}\right)-B(j)\right] * K
$$

Since $j^{\prime} \leq j$ and since we are considering the case in which group contracts are strictly preferred before the change in sanctions, $B\left(j^{\prime}\right) \geq B(j)>\pi$ (from Equation (6)). We thus have: $\frac{\delta U_{g}}{\delta \gamma} \geq$ $\frac{\delta U_{g}}{\delta K}>\frac{\delta U_{i}}{\delta K}$.

\section{Proof of Proposition 6}

From Lemma 1 we know that, for a group of size $n$ the maximum loan size $L_{g}(n)$ is obtained at $j^{*}=n$ if $\pi \geq \frac{n(n-1)}{1+n(n-1)}$. For a group of size $n-1$, the maximum loan size $L_{g}(n-1)$ is obtained when $j^{*}=n-1$ if $\pi \geq \frac{(n-1)(n-2)}{1+(n-1)(n-2)}$. Since $\frac{n(n-1)}{1+n(n-1)}>\frac{(n-1)(n-2)}{1+(n-1)(n-2)}$, if $\pi \geq \frac{n(n-1)}{1+n(n-1)}$, the largest loans for both these group sizes require all members to succeed.

We know that the largest group loan for a given group size is given by (4). Therefore for $\pi$ larger than the above threshold, the largest group loans for each of these group sizes is therefore given by

$$
\frac{r}{B(n-1, n-1, \pi)} L_{g}(n-1)=\min (\rho, K+\gamma)
$$

and

$$
\frac{r}{B(n, n, \pi)} L_{g}(n)=\min (\rho, K+\gamma)
$$

If the values of $\gamma$ and $\rho$ are large enough for $L_{g}(n)>L_{i}$, then since $B(n, n, \pi)<B(n-1, n-1, \pi)$, $L_{g}(n)<L_{g}(n-1)$ and outreach is larger for the smaller group .

For a borrowers that requires a loan of size $L_{g}(n)$, we can use (5) to derive the utility gain from being in a group of size $(n-1)$ rather than a group of size $n$ as $[B(n-1, n-1, \pi)-B(n, n, \pi)] * K$ which is strictly positive. 


\section{References}

Armendariz de Aghion, Beatriz, and Jonathan Morduch (2005) The Economics of Microfinance (Cambridge, MA: MIT Press)

Baland, Jean-Marie, Rohini Somanathan, and Lore Vandewalle (2008) 'Microfinance lifespans: A study of attrition and exclusion in self help groups in india.' India Policy Forum 4, 159-210

Banerjee, A., E. Duflo, R. Glennerster, and C. Kinnan (2009) 'The miracle of microfinance? evidence from a randomized evaluation.' Department of Economics, Massachusetts Institute of Technology (MIT) Working Paper, May

Banerjee, Abhijit V., Timothy Besley, and Timothy W. Guinnane (1994) 'Thy neighbor's keeper: The design of a credit cooperative with theory and a test.' Quarterly Journal of Economics $109(2), 491-515$

Banerjee, A.V., and A.F. Newman (1993) 'Occupational choice and the process of development.' Journal of Political Economy 101(2), 274-298

Besley, Timothy, and Stephen Coate (1995) 'Group lending, repayment incentives and social collateral.' Journal of Development Economics 46(1), 1-18

Field, E., and R. Pande (2008) 'Repayment frequency and default in microfinance: evidence from India.' Journal of the European Economic Association 6(2-3), 501-509

Galor, O., and J. Zeira (1993) 'Income distribution and macroeconomics.' The Review of Economic Studies 60(1), 35-52

Ghatak, Maitreesh (1999) 'Group lending, local information and peer selection.' Journal of Development Economics 60(1), 27-50

Ghatak, Maitreesh, and Timothy Guinnane (1999) 'The economics of lending with joint liability.' Journal of Development Economics 60, 195-228

Ghate, Prabhu (2008) Microfinance in India: A State of the Sector Report 2007 (New Delhi.: Sage)

Giné, Xavier, and Dean Karlan (2009) 'Group versus individual liability: Long term evidence from philippine microcredit lending groups.' Economic Growth Center Discussion Paper 970

Grameen Bank (2009) 'Banking for the Poor: Grameen II.' http://www.grameen-info.org 
Kaas, R., and J.M. Buhrman (1980) 'Mean, median and mode in binomial distributions.' Statistica Neerlandica 34, 13-18

Morduch, Jonathan (1988) 'Does microfinance really help the poor? new evidence from flagship programs in bangladesh.' working paper

National Bank for Agriculture and Rural Development (1992) Guidelines for the Pilot Project for linking banks with Self Help Groups: Circular issued to all Commercial Banks (www.nabard.org: Mumbai)

Srinivasan, N. (2009) Microfinance in India: A State of the Sector Report 2008 (New Delhi.: Sage)

Stiglitz, Joseph (1990) 'Peer monitoring and credit markets.' World Bank Economic Review $4(3), 351-366$

Wright, Graham A.N., David Cracknell, and Stuart Rutherford (2006) 'Grameen II: Lessons From The Grameen II Revolution, Microsave, Briefing Note 8.' http://www .microsave .org/ briefing_notes 